\title{
Series-Fed Microstrip Array Antenna with Circular Polarization
}

\author{
Tuan-Yung Han \\ Department of Computer and Communication Engineering, Chienkuo Technology University, Chang-Hua City 500, Taiwan
}

Correspondence should be addressed to Tuan-Yung Han, arthurhan@ctu.edu.tw

Received 21 July 2011; Revised 3 November 2011; Accepted 5 November 2011

Academic Editor: Miguel Ferrando

Copyright ( 2012 Tuan-Yung Han. This is an open access article distributed under the Creative Commons Attribution License, which permits unrestricted use, distribution, and reproduction in any medium, provided the original work is properly cited.

\begin{abstract}
This study proposes a novel $2 \times 2$ array antenna design with broadband and circularly-polarized (CP) operation. The proposed design uses a simple series-fed network to increase the CP bandwidth without requiring one-by-one adjustment of each array element or a complex feed network. Selecting the appropriate spacing between each array element allows the proposed array antenna to generate $\mathrm{CP}$ radiation with a low axial ratio. Experimental results based on a prototype show that this $2 \times 2$ microstrip array antenna achieves a wide $3 \mathrm{~dB}$ axial ratio bandwidth of more than $10 \%$. Simulated data are also provided to confirm the measured results.
\end{abstract}

\section{Introduction}

Due to their attractive features, such as low profile, light weight, and ease of manufacturing using printed circuit techniques, microstrip array antennas have come into high demand for satellite communication applications. To generate circularly-polarized (CP) radiation from a microstrip array antenna, previous research recommends a simple design method that uses a corporate-fed network [1] to excite each array element simultaneously. To allow each array element to exhibit equal power amplitude and phase distribution, most corporate-fed networks employ transmission lines (of the same length) and power dividers. However, the $\mathrm{CP}$ bandwidth of an array antenna design with a corporatefed network is usually limited to that of a single array element. Thus, previous studies propose the method of applying sequential rotation techniques to the feed network to improve the $\mathrm{CP}$ bandwidth of an array antenna effectively [2-4]. Due to the sequentially rotated structure of the feed network (with a single feed point), the phases of the four array elements $(2 \times 2$ array) are usually orientated sequentially at $0^{\circ}, 90^{\circ}, 180^{\circ}$, and $270^{\circ}$. This offers an impedance bandwidth approximately three times wider than that of a single array element. In this design, the designated array element can be either linearly polarized (LP) [5] or CP type. If an LP array element is used, the design process of the array antenna (with sequential rotation technique) will be easier than that for the $\mathrm{CP}$ array element type. This is because the process of adjusting the $\mathrm{CP}$ performance of each array element can be avoided. However, the resulting compound array gain is $3 \mathrm{~dB}$ lower than the array using the $\mathrm{CP}$ element. Sequential rotation of radiating elements can increase the input impedance bandwidth and polarization purity and achieve a good symmetrical radiation pattern [6]. However, a sequential rotation feed network must provide a delay line to allow various feed point with different phases to connect to each array element. This results in a relatively complicated circuit layout compared to the traditional corporate- or series-fed network. Several studies indicate that a corporatefed array antenna using sequential rotation techniques $[7,8]$ can improve the bandwidth of a corporate-fed array antenna and enhance the purity of polarization. However, disadvantages such as a complex feed network still exist, creating the possibility of producing multiple reflections between the element and the feed.

This study proposes a novel $2 \times 2 \mathrm{CP}$ microstrip array antenna design using series-fed lines. Experimental results show that the proposed array design and one using sequential rotation-fed network achieve similar levels of CP performances, including CP bandwidth and peak gain. Since the proposed array is fed by a simple series-fed network, there is no need for an elaborate phase shifting or power dividing circuit. This study presents both simulated and measured results for the proposed design. 


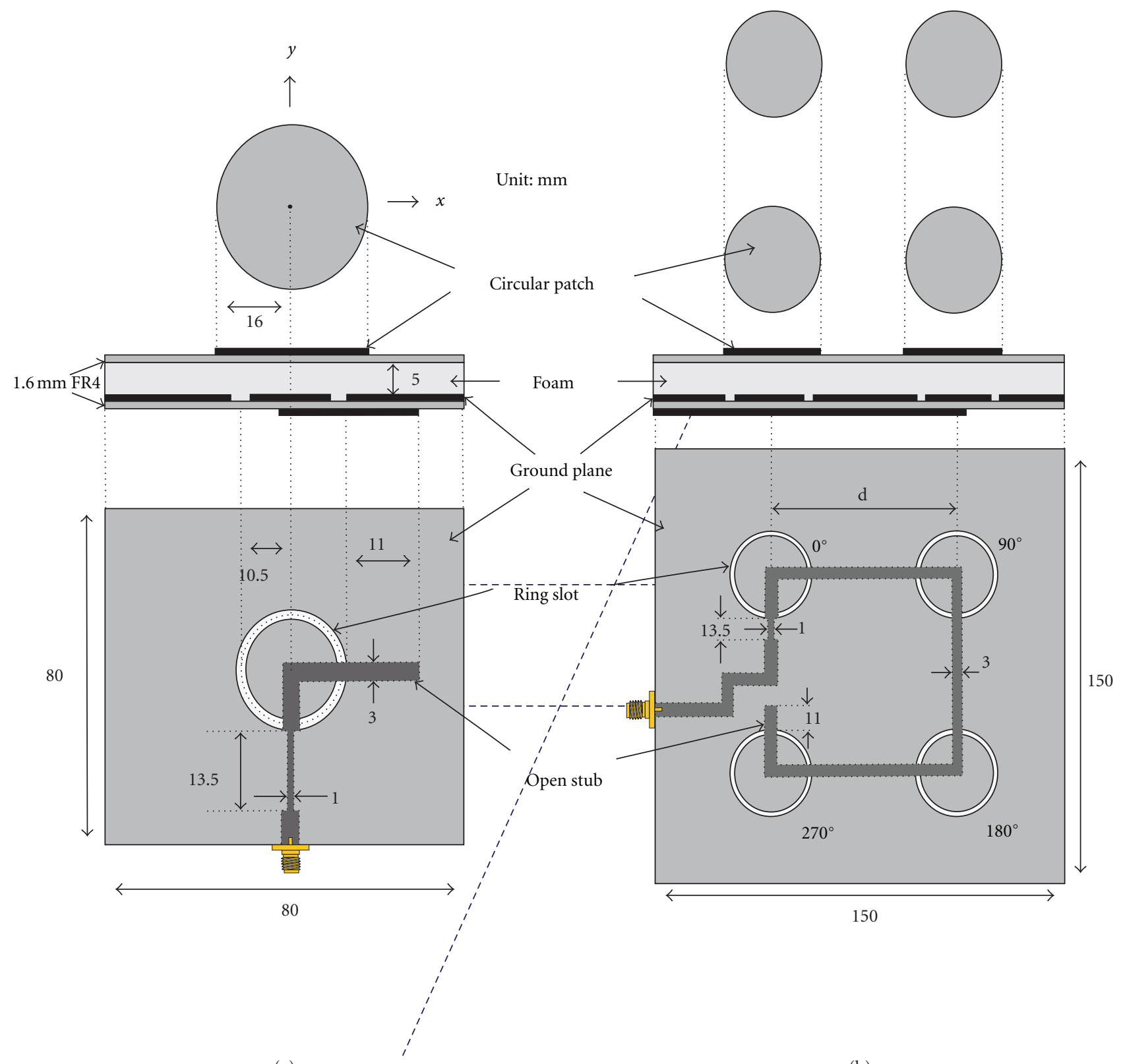

(a)

(b)

FIGURE 1: Geometry of the studied microstrip antennas. (a) Single ring-slot-coupled microstrip antenna. (b) $2 \times 2$ CP microstrip array antenna.

\section{Array Element Structure}

Figure 1(a) illustrates the geometry of a single aperturecoupled microstrip antenna. Two orthogonal modes of the antenna can be excited in series by a microstrip feed line through the coupling of the annular-ring slot in the ground plane. Choosing appropriate length (optimum at $11 \mathrm{~mm}$ ) for the open stub in the feed line allows the antenna to generate good CP radiation. A previous study analyzes the parameters and design procedure of this aperture-coupled microstrip antenna [9]. A prototype was first fabricated according to the dimensions revealed in Figure 1(a). Figure 2 shows the measured results along with the simulated results, which were generated using IE3D software. Experimental results indicate that the $\mathrm{CP}$ operating bandwidth of the prototype (also defined as $3 \mathrm{~dB}$ axial ratio) is approximately $150 \mathrm{MHz}$ (5.1\%) with respect to the center frequency measured at $2950 \mathrm{MHz}$. Since the prototype is microstrip-fed, it can be arranged in an array element manner.

\section{New Array Design and Results}

Figure 1(b) depicts the proposed CP microstrip array antenna. Four ring-slot-coupled microstrip antenna elements were excited through a series-fed network. Simulation results suggest that the element spacing, $d$, is the dominant parameter 


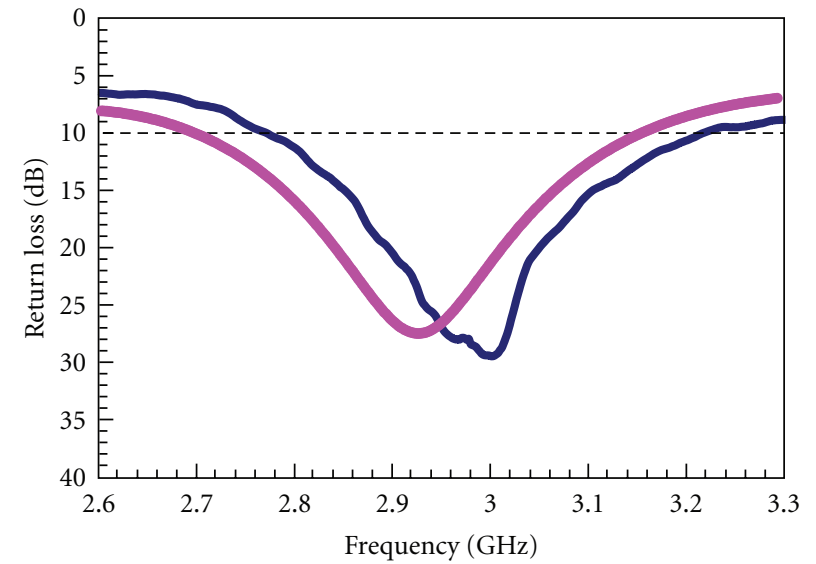

(a)

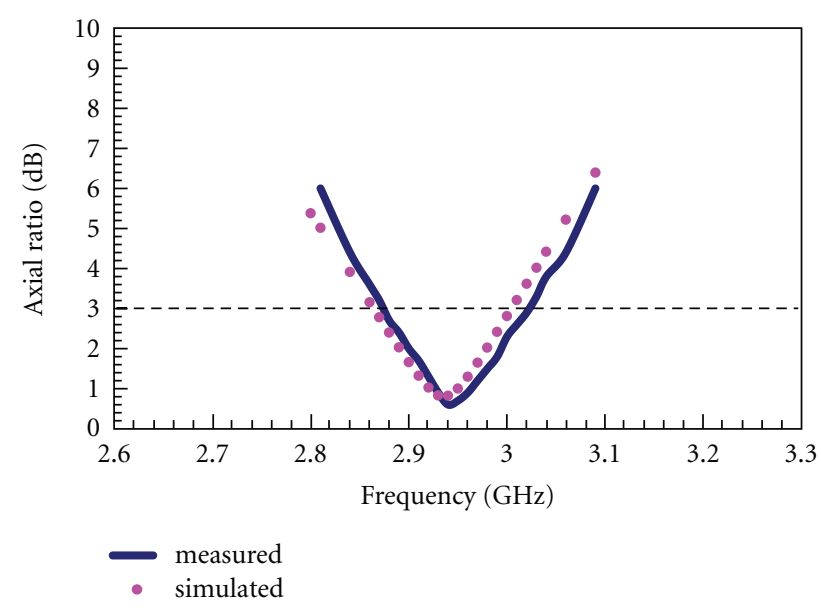

(b)

FIgURE 2: Measured and simulated results for the single CP ring-slot-coupled microstrip antenna. (a) Return loss. (b) Axial ratio.

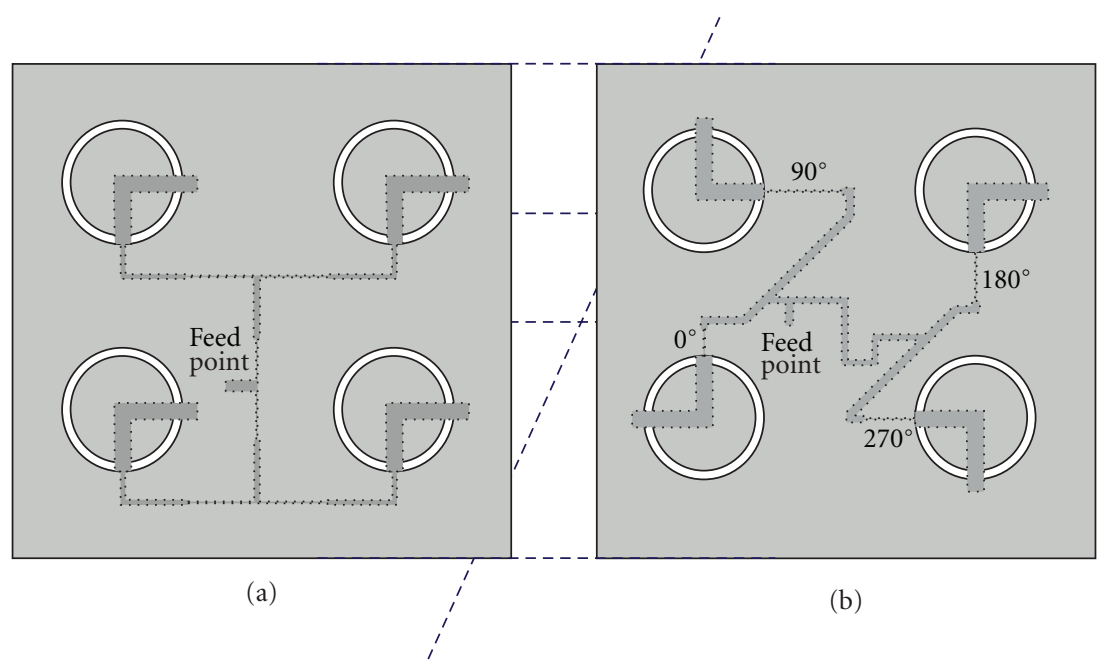

FIgURE 3: Structure of the reference antennas. (a) Corporate feed network, Array B. (b) Sequential rotation feed networks, Array C.

to determine the CP performance of the proposed array, and the optimum value is approximately $73 \mathrm{~mm}$ for the studied structure $\left(d \sim 0.76 \lambda_{0}\right.$, where $\lambda_{0}$ is referred to the center frequency of the $\mathrm{CP}$ operating bandwidth). To confirm the simulated results, a prototype (Array A) was constructed based on the dimensions presented in Figure 1(b). Two other prototypes, Arrays $\mathrm{B}$ and $\mathrm{C}$, using the corporate and sequential rotation feed networks, respectively, were also constructed as references (Figure 3). Except for different feeding networks, the three array prototypes were designed with the same structure, antenna dimensions, and element spacing. Due to the simplicity of series-fed network design, antenna engineers can ignore the process of adjusting the $\mathrm{CP}$ characteristics of each array element. However, the complex feed network designs in sequential rotational-fed and corporatefed array antennas necessitate tuning the $\mathrm{CP}$ performance of each array element.

Figures 4(a) and 4(b) present the measured return loss and axial ratio against frequency for the respective array pro- totypes. Figure also presents simulated results for Array A, indicating that they agree with the experimental results. These results confirm that all of the tested array prototypes have good impedance matching within their CP operating bandwidths. In addition, the CP bandwidth (4.7\%) of Array $B$ is almost the same as that of its array element, and the CP bandwidth (13.8\%) of Array C is about three times that of Array B. As for Array A, the CP bandwidth centered at $3110 \mathrm{MHz}$ is approximately $11.5 \%$ which is slightly less than that of Array C.

Figure 5 plots the measured radiation patterns of Array $A$ at $3110 \mathrm{MHz}$, revealing good left-hand CP (LHCP) radiations in the broadside direction. The main beam tilts slightly (about 3 degrees) to the left side in the $x-z$ plane. This might be because the array elements are not fed with an exactly equal power level. Nevertheless, the measured peak gain of Array A is approximately $12 \mathrm{dBi}$, which is only $0.3 \mathrm{~dB}$ lower than Array C. This small difference might be due to the feeding phase errors of each element. Table 1 summarizes the ex- 


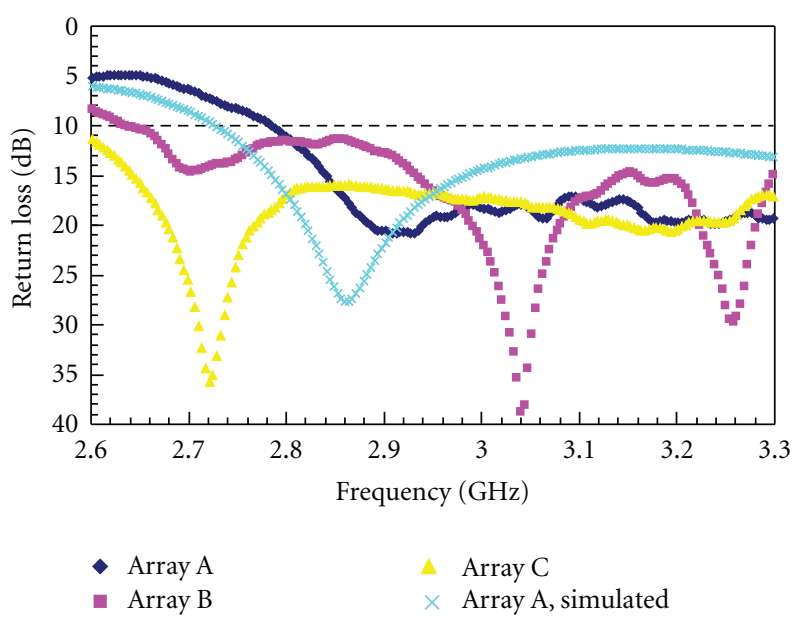

(a)

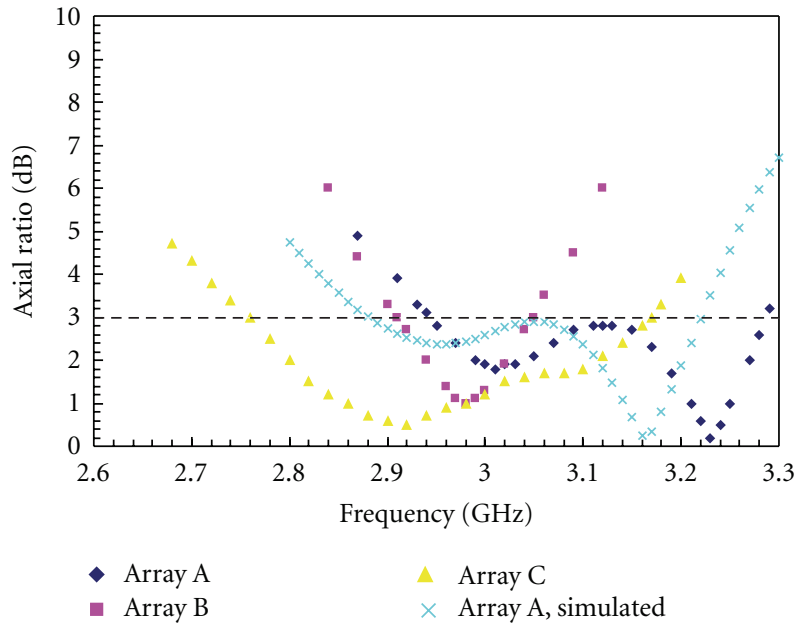

(b)

FIgURE 4: Measured results for the three array prototypes; $d=73 \mathrm{~mm}$. (a) Return loss. (b) Axial ratio.

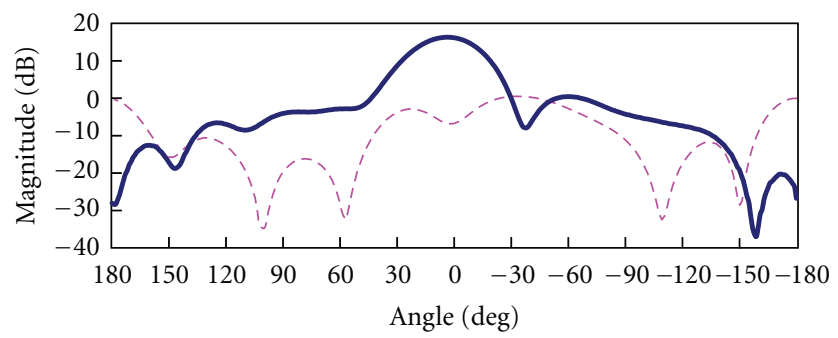

(a)

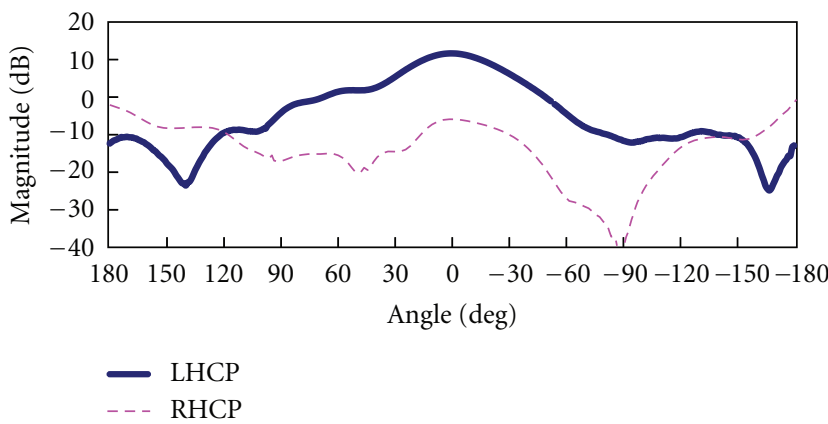

(b)

FIgURE 5: Radiation patterns of Array A measured at $3110 \mathrm{MHz}$. (a) $x-z$ plane. (b) $y-z$ plane.

TABLE 1: Experimental results for the studied single element and array prototypes.

\begin{tabular}{lccc}
\hline & $\begin{array}{c}3 \mathrm{~dB} \text { axial-ratio } \\
\text { bandwidth }(\mathrm{MHz}, \%)\end{array}$ & $\begin{array}{c}\text { CP center } \\
\text { frequency }(\mathrm{MHz})\end{array}$ & $\begin{array}{c}\text { Peak gain } \\
(\mathrm{dBi})\end{array}$ \\
\hline Single element & $150,5.1$ & 2950 & 7 \\
Array A & $360,11.5$ & 3110 & 12 \\
Array B & $140,4.7$ & 2980 & 12.4 \\
Array C & $410,13.8$ & 2965 & 12.3 \\
\hline
\end{tabular}

perimental results of CP performance for all three array prototypes. These results show that the CP bandwidth of Array $\mathrm{A}$ is approximately $6.8 \%$ larger than that of Array B, and 2.3\% smaller than that of Array C. Although array A demonstrates a slightly narrower bandwidth than array C, its peak gain measured in the boresight direction is almost similar (compared to Arrays B and C) at approximately $12 \mathrm{dBi}$. Array A also possesses a very simple feed network structure that does not require other circuit features, such as phase shifting or power dividing circuits. Thus, Array A is a preferred candidate compared to Array $\mathrm{C}$ if a simple feed network structure is required.

\section{Conclusions}

This study presents a $2 \times 2$ circularly polarized microstrip array antenna using a series-fed network. Experimental results indicate that this array has a broad CP operating bandwidth and an acceptable antenna gain. Moreover, the proposed design is relatively simple compared to the traditional array antenna, which uses a corporate or sequential rotation feed network.

\section{References}

[1] P. S. Hall and C. M. Hall, "Coplanar corporate feed effects in microstrip patch array design," IEE Proceedings $H$, vol. 135, no. 3, pp. 180-186, 1988.

[2] J. W. Baik, K. J. Lee, W. S. Yoon, T. H. Lee, and Y. S. Kim, "Circularly polarised printed crossed dipole antennas with broadband axial ratio," Electronics Letters, vol. 44, no. 13, pp. 785-786, 2008.

[3] M. Elhefnawy and W. Ismail, "A microstrip antenna array for indoor wireless dynamic environments," IEEE Transactions on Antennas and Propagation, vol. 57, no. 12, pp. 3998-4002, 2009.

[4] R. Caso, A. Buffi, M. Rodriguez Pino, P. Nepa, and G. Manara, "A novel dual-feed slot-coupling feeding technique for circularly polarized patch arrays," IEEE Antennas and Wireless Propagation Letters, vol. 9, pp. 183-186, 2010. 
[5] J. Huang, "A technique for an array to generate circular polarization with linearly polarized elements," IEEE Transactions on Antennas and Propagation, vol. AP-34, pp. 1113-1124, 1986.

[6] H. Evans, P. Gale, and A. Sambell, "Performance of $4 \times 4$ sequentially rotated patch antenna array using series feed," Electronics Letters, vol. 39, no. 6, pp. 493-494, 2003.

[7] D. C. Chung, S. Y. Choi, Y. H. Ko, J. H. Lee, and M. H. Kwak, "Circularly polarized HTS microstrip antenna array," IEEE Transactions on Applied Superconductivity, vol. 13, no. 2, pp. 301-304, 2003.

[8] M. N. Jazi and M. N. Azarmanesh, "Design and implementation of circularly polarised microstrip antenna array using a new serial feed sequentially rotated technique," IEE Proceedings: Microwaves, Antennas and Propagation, vol. 153, no. 2, pp. 133$140,2006$.

[9] J. S. Row, "Design of aperture-coupled annular-ring microstrip antennas for circular polarization," IEEE Transactions on Antennas and Propagation, vol. 53, no. 5, pp. 1779-1784, 2005. 

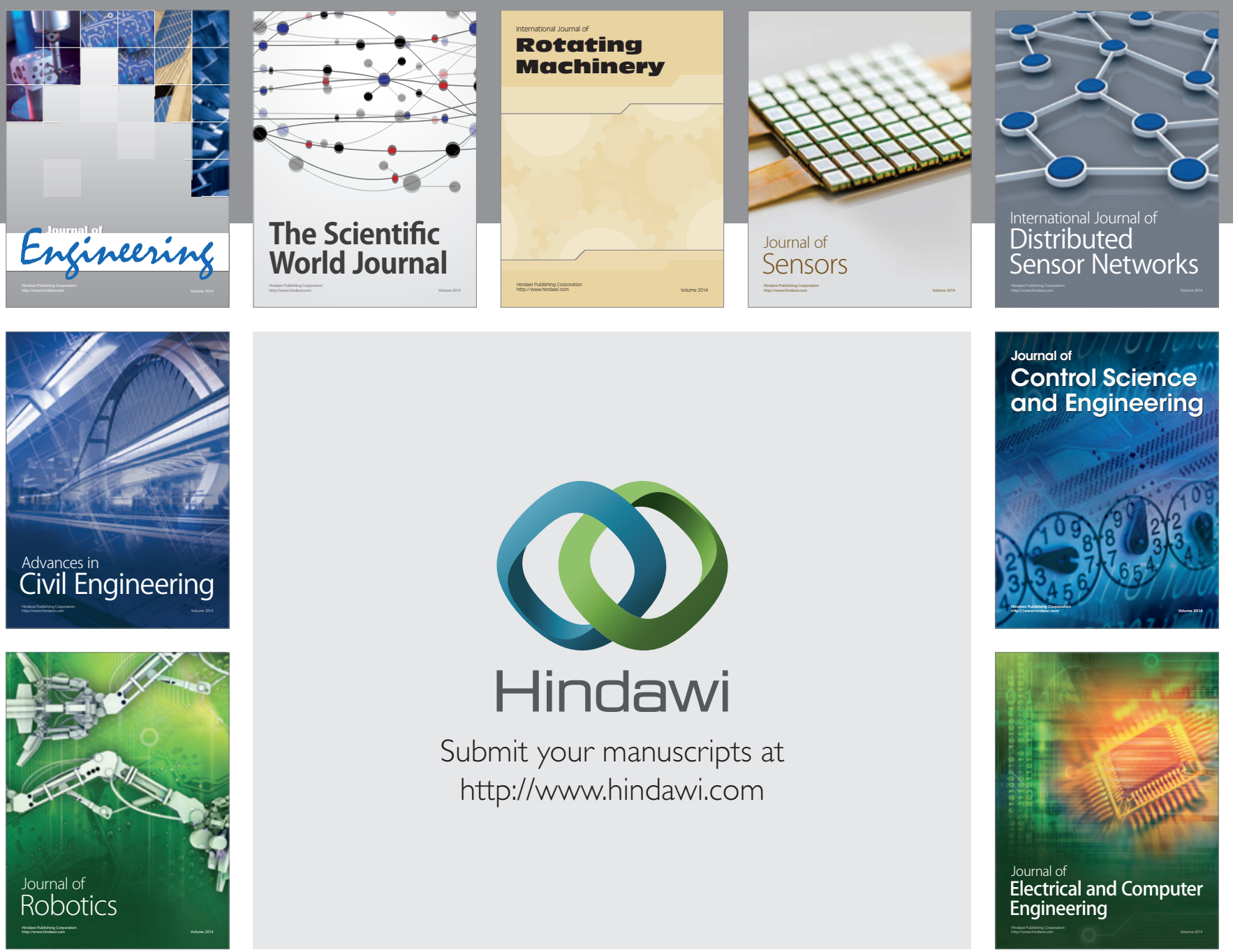

Submit your manuscripts at

http://www.hindawi.com
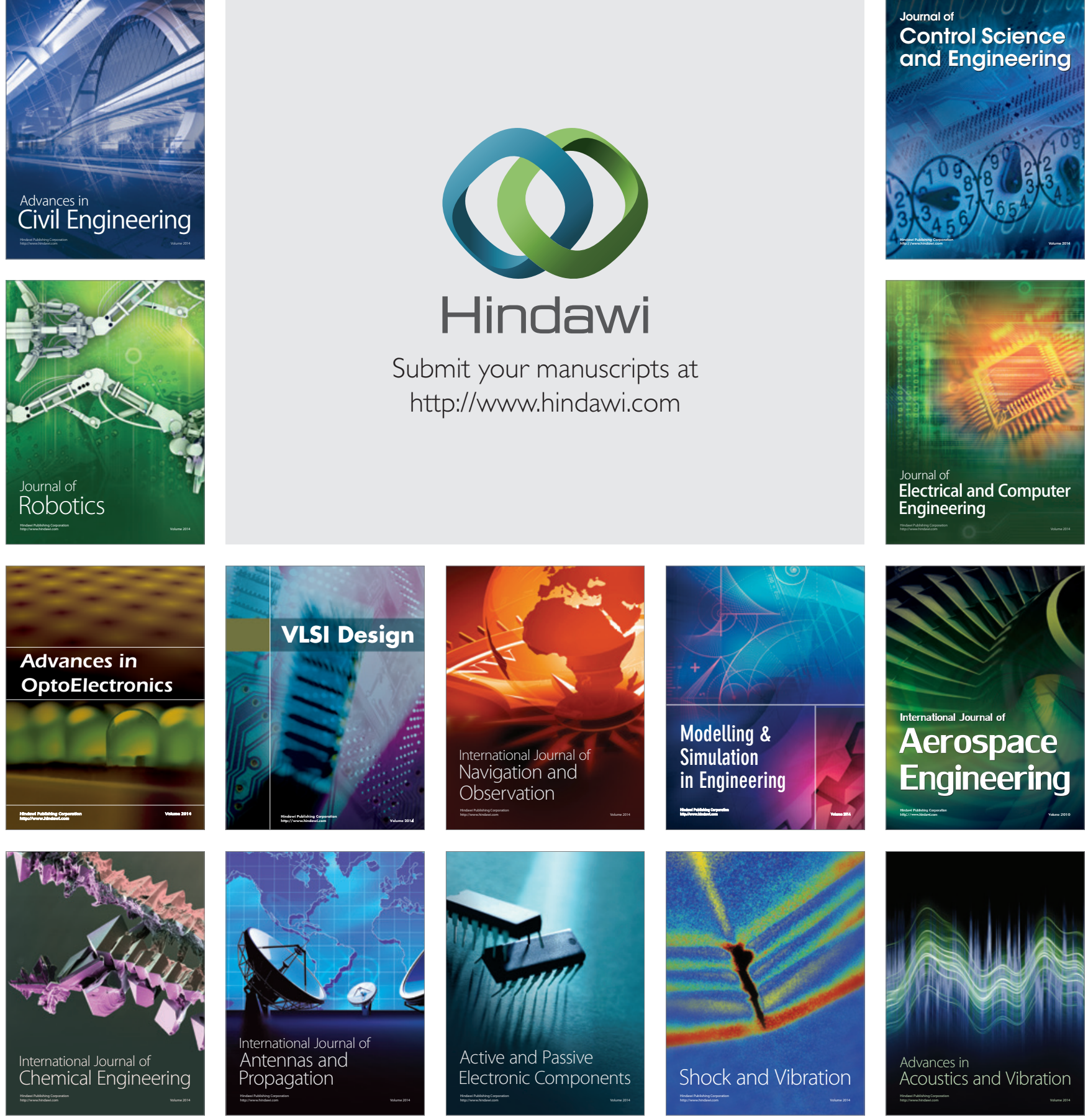